\title{
How are we going to do this?
}

Cite as: CMAJ 2021 July 12;193:E1052-3. doi: 10.1503/cmaj.210457

CMAJ Podcasts: author interview at www.cmaj.ca/lookup/doi/10.1503/cmaj.210457/tab-related-content

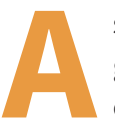

s I placed my son in his crib, I glanced around at all the medical equipment, and my husband's eyes locked on mine. We were both thinking the same thing: How were we going to do this? How were we going to take care of an almost two-year-old child on a ventilator, who had never lived outside a hospital intensive care unit? How were we going to handle it without a team of specialists available at the push of a button?

Our son had been in hospital for 500 days. Before he could be discharged, my husband and I had to undergo extensive training on all his medical care and equipment. We learned what acronyms such as "PIP" and "PEEP" meant on his ventilator; we learned what all the alarms were telling us and how to troubleshoot them. We learned how to give him oxygen and life-saving breaths with a resuscitation bag while calling 911 if required. However, all the newly acquired knowledge and skills did little to alleviate the overwhelming sense of dread and fear that we could not do it.

It was not an idle fear. We had already messed up on a one-night trial run. We had brought our son safely home but one of his alarms kept beeping and we couldn't figure out what was wrong. That night, my husband and I argued.

"I don't know what to do - do you?"

"I have tried everything I know! Should we call the hospital for help?"

"No, we can't do that - they'll never let us take him home again."

Years later, reflecting on that night, I wondered about our fear of failure that had driven us to hesitate before seeking help. At the hospital, the ICU staff told us we should have sought help immediately, but more importantly, they reassured us that they were there to help us, not judge us. Up until that point, my husband and I

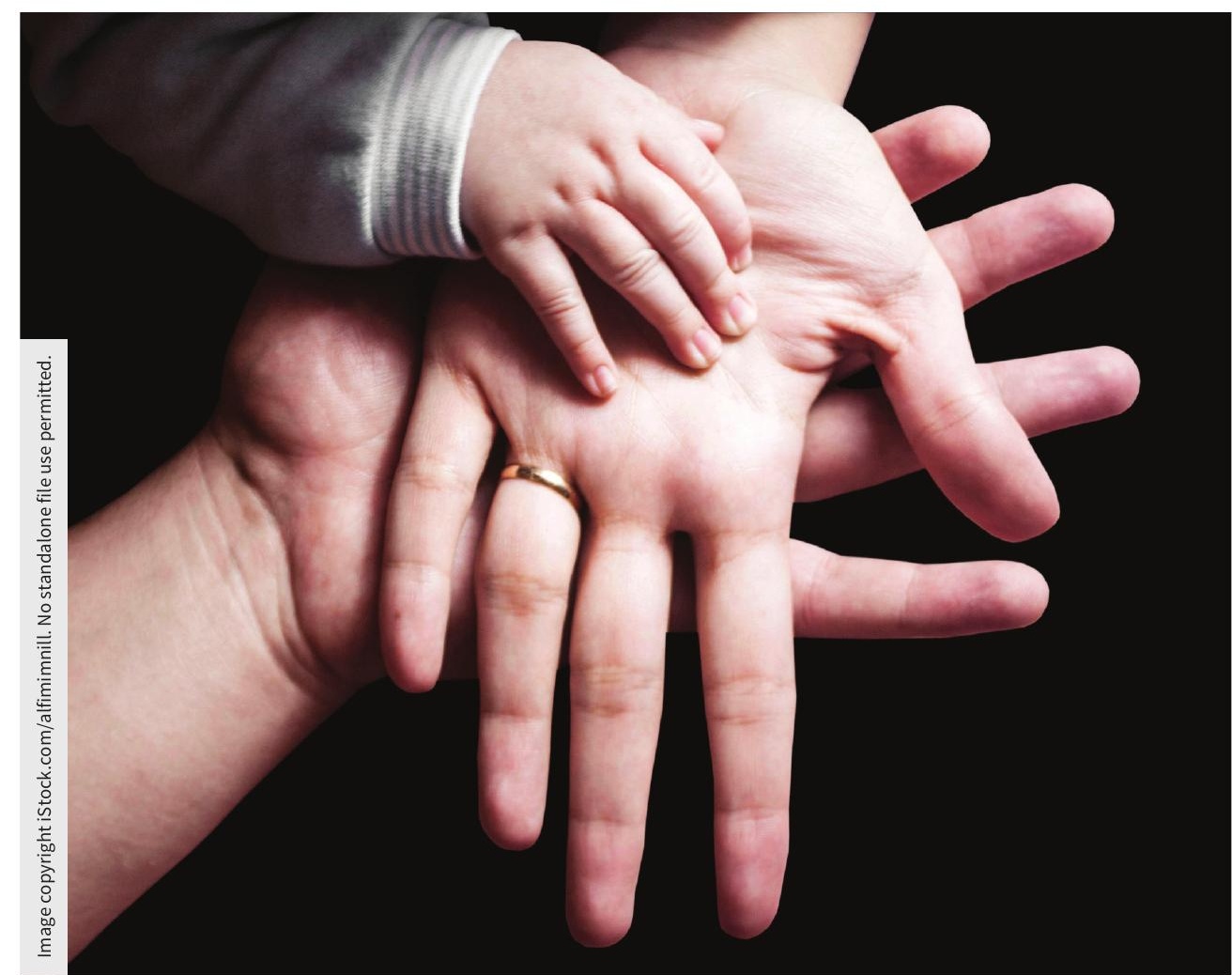

had not realized that the doctors understood the importance of us living at home together, even with all this complicated equipment. They trusted us to handle it and wanted to support us to prove to ourselves that we could meet the challenge and be independent. Our doctors wanted us to succeed at home, but I am not sure they knew what home was really going to look like for us once the ICU was no longer directly supporting us.

When our son was discharged from the ICU, we had a $24 / 7$ hotline to respiratory therapists trained on his ventilator. If we had a question, we could contact a specialist on call at the hospital. The local health unit sent us a nurse five nights a week to watch our son while we slept. But those supports did little to minimize the uncertainty that arose when a problem came up. Years after discharge, my husband and I still had the same arguments about when and where to seek care. Was this a problem easily solved over the phone? Did they need to actually see him? Was it safer to keep him at home, rather than move all his medical equipment into the car? If we called 911 or brought him to the emergency department, would he receive care from people experienced with children like him? The answers never came easily, and the anxiety persisted.

All these feelings, the memories of those arguments, the long nights: it was all these experiences that made me think I might be able to suggest changes in how patients on ventilation are supported when they first get home. I connected with 
a team of researchers who listened to my concerns and were intent on finding solutions. What we needed was a way to get essential support in our home. We had all the equipment; we knew the challenges with seeking care - we just needed the permission and ability to reach out to the right people in our time of need.

I could have simply shared my idea with them and returned to my life as a student, wife and medical mom. But I didn't. I wanted to learn what it would take to turn an idea into reality, and how you uncover the evidence to determine the right solution. I also hoped they could learn from me: why I thought this idea was the right one, what is important to families like ours, and how to help keep kids like mine front and centre when designing a solution. I learned about the challenges of obtaining funding: the contracts, paperwork and approvals. I saw first hand why health care innovations take so long to reach the patient.

As a team, we learned that it is important to get things right from the start. Integrating patient input at the end is like putting patches on a leaky boat. You need to design with patients' needs in mind from the start, because it can change everything. I remember saying early on, "You are not moving your processes online - you are redesigning how you care. You are not transitioning from answering questions on the phone to text - you are supporting the patient and families to feel more confident in their own skills and building a technologyenabled support system." Until this point, the main consideration had been how to deliver care safely; from that point on, it was how to make patients and their caregivers feel safe. That simple premise had a profound impact.

I did not always feel confident about sharing my perspective. I had been invited to participate, but that didn't mean I felt I should be there. I justified my seat from the start, introducing myself by saying, "I am the mom to a little boy who is vented $24 / 7$, and I'm a PhD student studying health research." I felt that these dual roles gave me the credibility to share my ideas. I continued to preface every comment with, "from the parent's perspective ...". In part, I did that to alert clinicians that they "may not see it like this, but ...," and I wanted to shield myself from being judged for potentially giving a poor recommendation. But mostly I did it because I wanted to ensure they didn't dismiss my input. I also wanted to make it clear that I was not speaking for an entire population of patients and caregivers. I recognized my experience as a cis-female, married parent of an only child. I was not a patient; I was not a caregiver to a spouse or single parent. I was a person with lived experience who had access to a team willing to listen to me. I wanted to open the door to the stories of patients and hold it open for others to follow.

I don't think we can correlate the success or failure of the Long-Term In-Home Ventilation Engagement (L.I.V.E.) program with any of my suggestions, but I can see some of my recommendations in the final product. Our feelings of uncertainty were reflected in the clinical intervention: we now ensure patients have permission to contact their clinical team on their own terms, to reach out without judgment. I felt listened to and heard, my suggestions thoughtfully considered and debated. I witnessed the process from beginning to end, and I saw the struggles that led to compromises in the final product. I am proud of it and maybe that is the only way to measure whether my participation was a success.

Did I feel I made a difference? Was it worth my time? Did I feel part of the team? I can confidently answer "yes." But my case is particular to my circumstances. If I had a different level of education or did not understand the lingo of research, would the research team still have wanted me on the team? Would they have invested the time to teach me the skills I needed to be involved? If I could not afford to attend meetings as an unpaid volunteer, would they have been willing to pay me to contribute? From my perspective, my answer is yes, I did make a difference. But my perspective was confined to this one project. It is up to the next research team to invite me, or my cohorts, into the conversation. It is up to them to include me, pay me, or use my input. It would be much easier for them to host a focus group, give everyone a $\$ 10$ gift card and then not have to explain why their input was not included.

We know that including the perspectives of patients and families is good for research. However, how we engage patients is still evolving. Introducing a new voice into a research process that has gone unchanged for decades is complicated. Change involves revising funding models, hiring practices, incentives, and the way people think about the role that patient and family play in medicine. It means measuring the outcomes of health interventions to include, cultivate and value the patient and family perspective. Is all this change worth it? This is the challenge of patient engagement.

\section{Francine Buchanan MLIS}

The Hospital for Sick Children; Institute of Health Policy, Management and Evaluation, University of Toronto, Toronto, Ont.

This article has been peer reviewed.

Note: This article is a reflection on the role of patient and family advisory in health research and innovation. To learn more about the intervention that was developed as a result of this partnership, see Amin et al. "A virtual care innovation for home mechanical ventilation." CMAJ 2021;193:E607-11. doi: 10.1503/cmaj.202584.

Content licence: This is an Open Access article distributed in accordance with the terms of the Creative Commons Attribution (CC BY-NC-ND 4.0) licence, which permits use, distribution and reproduction in any medium, provided that the original publication is properly cited, the use is noncommercial (i.e., research or educational use), and no modifications or adaptations are made. See: https://creativecommons.org/ licenses/by-nc-nd/4.0/ 